\title{
한국 사랑의 집짓기 운동연합회 (Habitat For Humanity Korea) 소개
}

\section{강 용 상 / 한국해비타트 사업관리팀장}

\section{1. habitat (해비타트) 란?}

전 세계에 흩어져 있는 무주택 서민들의 주거 문제를 해결할 목적으로 미국의 변호사인 밀러드 풀러(Millard Fuller)와 그의 부인 풀러(Linda Fuller)가 1976년 창설한 초교파적인 민간 기독교 운동 단체입니다. 사전적 의미는 '거주지' 로 보금 자리를 의미합니다.

밀러드 부부는 20 대 후반에 이미 많은 재산을 모 았으나, 인류를 위한 참다운 삶을 찾기로 결심했습 니다. 1965 년 전 재산을 팔아 가난한 사람들에게 나누어 준 뒤, 미국 조지아주의 시골인 아메리쿠스 의 변두리에 koinonia farm 이라는 기독교 공동체 로 들어가서 살기 시작했고 1973년 아프리카 자이 르(현 콩고민주공화국)로 건너가 가난한 흑인들을 위해 집을 지어쥤습니다. 이어 1976년 오늘날의 모 습을 갖춘 국제 해비타트를 창설해 개인 - 교회 · 기업 및 각종 사회단체와 힘을 합쳐 가난한 이웃을 도와 그들의 가정에 희망의 보금자리를 제공하기 시작하면서 국제적인 운동으로 자리 잡았습니다.

\section{2. 국제 해비타트 소개}

- 1976년 설립 - 설립자 밀러드 풀러 부부

- 1984년 전 미국 대통령 지미카터( jimmy carter)부부가 뉴욕에서 해비타트에 자원봉 사로 참가하기 시작 - jcwp(jimmy carter work project) 시작

- 1989년 미국 남부의 허리케인 휴고가 지나간 후 해비타트 주택이 건재하였다는 뉴스를 통 하여 유명해짐

- 1993년 20,000번째 주택 건축

- 1994년 30,000번째 주택 건축

- 1999년 80,000번째 주택 건축

- 2000년 100,000번째 주택 건축

- 2001년 jcwp 한국에서 개최

- 2005년 200,000번째 주택건축 : 20여분에 한 채 꼴로 건축되고 있음. 현재 100 여개의 국가에 조직이 있음. 전 세계적으로 2,300 여개의 지회가 활동 중. $1,000,000$ 여명의 입주자들에게 혜택을 부여함. 


\section{3. 한국 해비타트 소개}

1976년 국제해비타트가 창설된 지 10년여가 지 난 1980년도 후반 우연한 기회로 한국에서도 해비 타트운동 탄생의 기운이 싹트기 시작했습니다.

예수원 원장이었던 대천덕 신부(R.A.Torrey) 가 그의 저서〈산골짜기에서 온 편지〉에서 해비타트
운동을 소개했는데, 후에 해비타트의 실행위원장 을 지내기도 했던 고왕인 박사가 이 글을 읽고 한 국에서의 해비타트의 필요성을 느끼고 헌신하게 되었습니다.

1992년 1월에 과기처장관을 지낸 정근모 박사 를 이사장으로 추대하여 정식기구로 발족했고,

〈표1. 국내 건축 사업〉

\begin{tabular}{|c|c|c|c|c|c|c|c|c|c|c|c|c|c|}
\hline 구분 & 의정부 & 태백 & 진주 & 서울 & $\begin{array}{l}\text { 전남 } \\
\text { 동부 }\end{array}$ & $\begin{array}{l}\text { 대구/ } \\
\text { 경북 }\end{array}$ & $\begin{array}{l}\text { 천안/ } \\
\text { 아산 }\end{array}$ & 파주 & 군산 & 삼척 & 강릉 & 춘천 & 소계 \\
\hline 1994 & 3 & & & & & & & & & & & & 3 \\
\hline \multicolumn{14}{|l|}{1995} \\
\hline 1996 & 4 & & & & & & & & & & & & 4 \\
\hline 1997 & 4 & 2 & & & & & & & & & & & 6 \\
\hline 1998 & 4 & 6 & & & & & & & & & & & 10 \\
\hline 1999 & 4 & 3 & 4 & 5 & & & & & & & & & 16 \\
\hline 2000 & & 5 & & & 32 & & & & & & & & 37 \\
\hline 2001 & 9 & 12 & 16 & & & 17 & 88 & 12 & 12 & & & & 166 \\
\hline 2002 & & 8 & & & & 12 & 16 & 4 & & & & & 40 \\
\hline 2003 & & & 4 & 8 & & 4 & & & 8 & 20 & 20 & & 64 \\
\hline 2004 & & 6 & 8 & & & 8 & 16 & & 4 & & & 8 & 50 \\
\hline 2005 & & 8 & & 6 & & 4 & 16 & & & 4 & & 8 & 46 \\
\hline 소계 & 28 & 50 & 32 & 19 & 32 & 45 & 136 & 16 & 24 & 24 & 20 & 16 & 442 \\
\hline
\end{tabular}

〈표2. 국외건축 사업〉

\begin{tabular}{|c|c|c|c|c|c|c|c|c|c|}
\hline 구분 & 필리핀 & 남아공 & 몽골 & 인도네시아 & 태국 & 인도 & 스리랑카 & 미국 & 소계 \\
\hline \multicolumn{10}{|l|}{1994} \\
\hline 1995 & 5 & & & & & & & & 5 \\
\hline 1996 & 52 & & & & & & & & 52 \\
\hline 1997 & 27 & & & & & & & & 27 \\
\hline 1998 & 33 & & & & & & & & 33 \\
\hline 1999 & 13 & & & & & & & & 13 \\
\hline 2000 & 30 & & & & & & & & 30 \\
\hline 2001 & 16 & 10 & & 2 & & & & & 28 \\
\hline 2002 & 24 & & 10 & & & & & & 34 \\
\hline 2003 & 21 & & 13 & & 7 & & & 3 & 44 \\
\hline 2004 & 17 & & 51 & & 2 & & & & 70 \\
\hline 2005 & 31 & & 23 & 1 & & 1 & 2 & & 58 \\
\hline 소계 & 269 & 10 & 97 & 3 & 9 & 1 & 2 & 3 & 394 \\
\hline
\end{tabular}


1994년에 경기도 의정부에 첫 번째 한국해비타트 주택이 건축되었습니다.

1995년에 건교부 산하의 비영리공익법인으로 정식 인가를 받아 본격적인 활동을 시작했고, 이듬 해인 1996년에는 필리핀에 5 세대의 집을 지어 줌 으로써 해외지원사업의 시초가 되었습니다.

\section{4. 사업실적 : 표1, 2 참조}

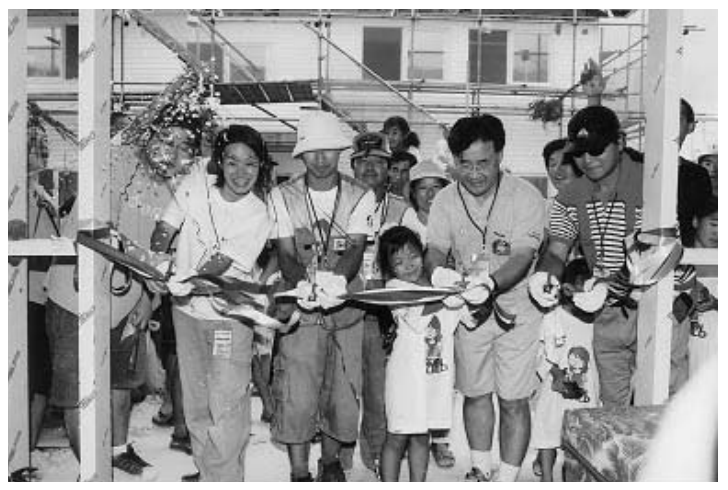

\section{5. 해비타트의 미션}

전 세계의 해비타트는 다음과 같은 공통된 사 명(Mission)을 가지고 일을 하고 있습니다.

해비타트는 전 세계 다양한 분야에 종사하는 사람들이 협력하여 도움이 필요한 입주가정들에게 집을 신축하거나 개조함으로써 입주가정들이 하나 님이 의도한 안락한 집과 건전한 지역사회 환경에 서 살 수 있도록 하는데 사역의 목적이 있습니다.

\section{6. 한국 해비타트의 비전}

해비타트는 지역사회의 계층간의 화합과 공동 체회복을 위한 운동입니다. 땀의 현장에서 다양한 사람들과 함께 일하면서 자신을 희생하고 동역하
는 법을 배우면서 자신도 모르게 해비타트가 이루 고자 하는 것을 공유하고 그 안에 예수님의 가르침 이 있다는 것을 자연스럽게 느낄 수 있도록 하는 것입니다. "행동하는 사링" 해비타트는 이렇듯 새 로운 선교의 장을 열고자 합니다.

해비타트는 지회가 설립되어 있지 않은 지역 에서는 건축사업을 진행할 수가 없습니다. 해비 타트는 지역에 기반을 둔 지역공동체 안에서의 협력운동이기 때문입니다. 열악한 주거환경에 신 음하는 상황을 완전히 몰아내는 것이 해비타트의 사명이기에 예수님의 사랑의 손길이 미치지 않는 곳이 없도록 가능한 많은 곳에 지회를 설립하고 자 합니다.

한 세대의 해비타트 주택에는 500여명의 자원 봉사자의 손길이 담겨져 있습니다. 수 백명의 망치 질이 커다란 건설장비의 역할을 해내듯, 해비타트 는 한 사람의 많은 후원금보다는 작은 정성들이 모 여 더 큰 사랑을 이룰 수 있는 새로운 기부문화를 만들고자 합니다.

경쟁에 익숙한 한국의 젊은이들에게 사회 안에 서 더불어 사는 법을 알려주고 이웃사랑의 의미를 깨닫게 함으로써 건강한 사회를 만드는 구성원으 로 이끌고자 합니다. 각계 각층에서 참여한 자원봉 사자들과 함께 땀을 흘리며 다양한 분야의 건축공 정을 경험하면서 합리적인 의사결정과정을 배우 고, 입주가정과 기쁨을 함께 하면서 이상적인 사회 상을 정립할 수 있을 것입니다.

해비타트 운동은 단순히 집을 짓는 것에 그치는 것이 아닌, 가정을 새롭게 일으키고 계층간의 화합 
과 나눔의 방법을 배워 나간다는 점에서 정부에서 진행하는 그것과는 많은 차이가 있습니다. 해비타 트 운동을 통해 축적된 이러한 역량들은 통일 이후 북한의 주택문제를 슬기롭게 대처할 수 있는 기초 가 될 것입니다.

\section{7. 해비타트 12 가지 원칙}

해비타트의 목표는 주택을 건설, 열악한 주거환 경과 집 없는 사람들을 지구상에서 없애고, 소박한 주택의 건설을 양심과 실제적인 문제로 만드는 것 입니다. 이와 같이, 다음과 같은 기본원칙들이 해 비타트 사역의 근간을 이루고 있습니다.

\section{1) 기독교 운동}

해비타트는 기독교 운동입니다. 예수님 중심의 운동입니다.

우리는 예수 그리스도의 사랑과 가르침을 모든 사람에게 전하기 위해 노력합니다. 해비타트 운동 은 인간의 정의감에 근거하거나, 인간의 동정심에 호소해서 유지되는 운동이 아니라고 믿습니다.

해비타트운동이 여타의 사회 운동과 다른 점은 예수 운동(Jesus movement)이라는 데 있습니다.

"여호와께서 집을 세우지 아니하시면 세우는 자 의 수고가 헛되며(시편 127:1)" 해비타트는 초교파 평신도 기독교 운동으로, 특정 교회나 교파에 매이 지 않습니다. 또한 다른 종교의 사람이나 신앙이 없는 사람들도 참여하실 수 있습니다.

\section{2) 국제적인 협력 운동}

해외 워크캠프를 통해 자원봉사자 개인으로부 터 각 지회는 물론 국가의 연합회간에 이르기까지 모든 해비타트 조직들은 땀과 노하우 재원을 함께 합니다. 각 나라의 해비타트지회는 십일조를 통해 다른 지회를 돕습니다. 지회에서 모금한 자금의 적어도 $10 \%$ 를 다른 나라의 지회를 지원하는데 사용해야 한다는 뜻입니다.

\section{3) 공동체 건설}

해비타트 사역의 초점은 단순히 집을 건축하는 것이 아니라, 입주 가정뿐만 아니라 공동체의 모든 일원이 동역해서 서로의 물질적, 영적, 사회적 필 요를 채우도록 지역사회의 전반적 개발을 꾀합니 다. 이러한 목표를 달성하기 위해 각 지역의 자발 적인 헌신과 지역민들의 참여가 있어야 합니다.

그래서 해비타트의 주도권은 해당 지역의 지회 와 자원봉사자들에게 있습니다.

\section{4) 다양성과 포용성}

해비타트 지회는 해당 지역사회의 모든 집단의 목소리를 반영해야 함은 물론 경제 상황, 직업, 인 종, 성, 연령, 교파 등을 초월해 뜻을 같이 하는 개 인과 단체와 협력합니다.

\section{5) 동역 관계}

해비타트운동이 추구하는 바와 그 운동방법에 공감하여 나름의 방법으로 힘을 모으는 모든 개인 이나 집단은 우리의 동역자입니다.

지회, 이사, 위원회, 입주 가정, 교회, 기부자도 
동역자이고, 연합회, N.G.O.(비정부 조직), 학생 동아리와 청년단체, 시민단체, 정부도 동역자이며, 간사와 자원봉사자도 서로 동역관계에 있습니다.

해비타트 운동에서는 주는 쪽과 받는 쪽이 따로 있지 않습니다.

\section{6) 청지기 정신}

해비타트는 하나님이 맡기신 것을 성실하게 관 리함을 통해 하나님이 우리에게 주신 비젼과 사명 을 감당합니다. 청지기로서 우리에게 맡겨진 것에 는 시간, 재능, 기술, 자금, 토지, 인맥, 자연자원 등 모든 것이 포함됩니다. 따라서 연합회 및 지회의 자 금과 모든 자산은 투명하게 드러나야 하며, 다른 용 도로 전용할 수 없습니다. 해비타트는 우리의 재원 으로 보다 많은 집을 지을 수 있도록 자금, 자재, 노 동력 등 재원을 최대한 활용해야 하는 것입니다.

\section{7) 무이자 비영리로 주택 판매}

해비타트 주택에는 이자가 없기 때문에 저소득 가정이 입주할 수 있을 만큼 저렴할 수 있습니다.

\section{8) 소박, 안락, 저렴한 집}

'소박', '안락', '저렴' 의 의미는 각국이나 각 지 회에서 해당 지역의 기준에 따라 정합니다.

국내에서는 전용면적 15 평입니다. 해비타트는 건축비용을 더욱 낮추는 노력을 게을리 하지 않고, 소박하지만 양질의 주택건축방법을 방법을 찾도록 노력해야 합니다.

\section{9) 입주 가정은 가장 중요한 동역자}

입주자 및 입주 신청자들은 해비타트의 동역자 입니다. 해비타트는 단순히 입주자를 위해 집을 짓 는 것이 아니라, 입주자와 함께 집을 짓습니다.

입주자가 주택 상황을 개선시키겠다는 의지를 해비타트가 돕는 것입니다.

\section{0) 공평한 입주가정 선정}

자원봉사자들로 구성된 가정선정위원회는 세 가지 기준에 근거하여 입주신청자를 선정하되 종 교, 출신지역, 국적 등에 따른 차별은 없습니다.

첫째, 무주택 영세서민

둘째, 주택건설원가 분할 상환 능력

셋째, 500 시간 이상 건축 현장에 동참.

\section{1) 땀의 분담}

입주자는 자신의 집을 지을 때나 노동으로 참여 해야 합니다. 이것을 '땀의 분담(Sweat Equity)' 라고 부르는데, 건축비를 낮추고, 입주 가정이 자 기 집이라는 의식과 집에 대한 긍지를 높일 뿐 아 니라, 집을 유지하는데 필요한 기술을 얻는데 도움 을 줍니다. 입주자 상호간에, 입주자와 지회 조직 간에 그리고 입주자와 자원봉사자 간에 유대와 나 눔을 촉진합니다.

12) 회전 기금: 입주자의 상환금은 해비타트 회전기 금으로 다른 후원금과 함께 다시 다른 사람의 집을 짓는데 쓰이게 됩니다. 


\section{8. 한국 해비타트의 조직}

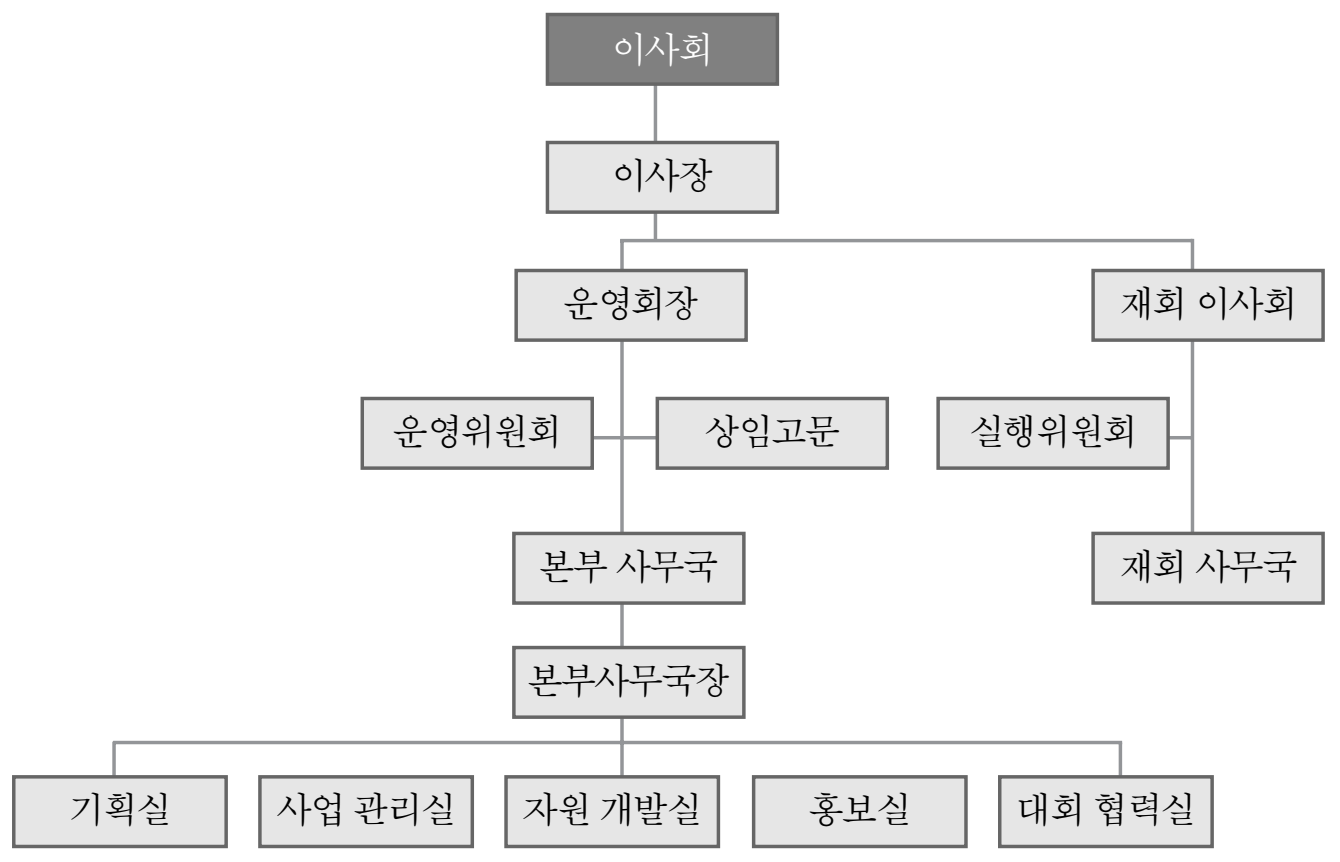

\section{9. 주요 사업소개}

\section{가. Korea Blitz Build (한국번개건축)}

한국번개건축은 사랑의 집짓기의 독특한 노하 우를 살린 대규모 단기건축프로젝트로 2002년부 터 매년 8월 초에 시작하여 일주일간 개최합니다.

이 프로그램은 여름 휴가와 방학을 이용해서 자 원봉사자들이 주택건축에 직접 참여할 수 있는 기 회를 제공합니다.

\section{나. 집고치기 프로그램}

수도권내 노후한 주거환경으로 인해 힘들어 하 는 소년·소녀가장, 독거노인, 장애인 가정 등을
주거환경 개선을 통해 행복의 기회를 넓히고자 하 는 프로젝트입니다. 직접 집을 수리하기 힘든 열악 한 주거 환경의 이웃을 돕고, 자신들의 소중한 시 간과 땀으로 일하는 자원봉사자들을 통해 이 사회 에 희망을 주고자 하는 프로젝트입니다.

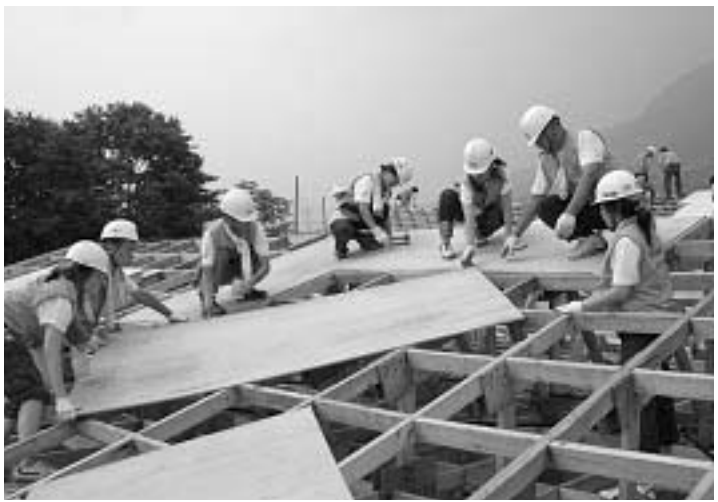




\section{다. Global Village (지구촌프로그램)}

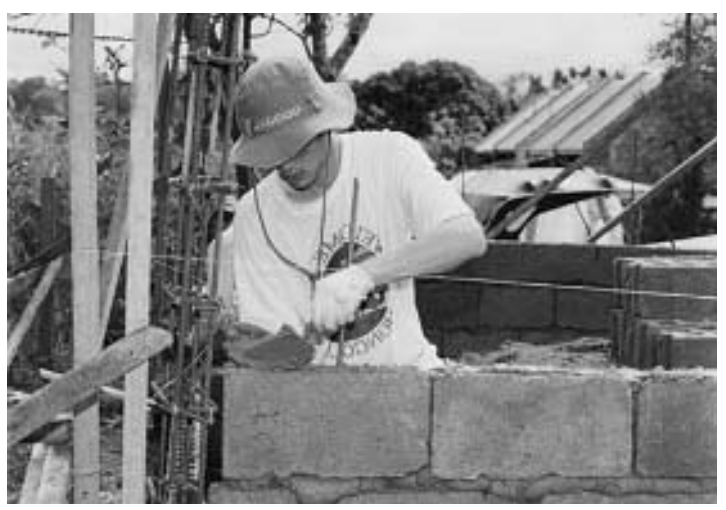

자원봉사자들을 세계 각국으로 파송하여, 사랑 의 집짓기 나눔 운동을 펼치는 단기 주택 건축 프로 그램으로 자원봉사자는 약 10 일간의 일정으로 집을 지으면서 현지 입주가정과 교류하게 됩니다. 지구 촌프로그램의 참가자들은 지회와 미래 입주가정과 함께 집을 건축하고 안락한 집의 필요성을 널리 인 식시키는 일을 함으로써, 문화적인 이해를 넓히고 상호 교류할 수 있는 좋은 기회를 갖게 됩니다.

\section{라. 자전거로 짓는 사랑의 집 (Cycling for Habitat)}

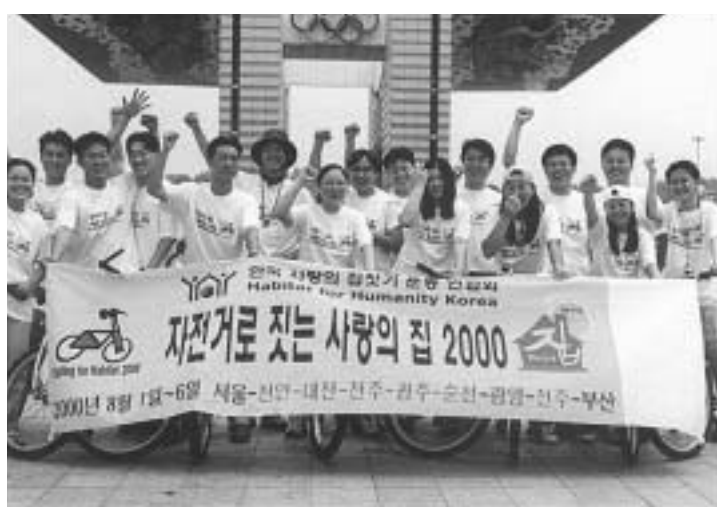

1주일간 Cycling을 통해 무주택 서민들을 위한 해비타트 주택의 건축기금 $(1 \mathrm{~km}$ 당 1,000 원을 모금
하는 bike-e-thon형식)을 마련하고 해비타트 운 동을 홍보하기 위한 프로그램으로써 한국의 대학 생들이 스스로 계획하여 실행하는 한국 해비타트 의 대표적인 청년 프로그램입니다.

\section{마. Building on Faith (믿음으로 짓는 집)}

해비타트와 협력 교회들이 하나님의 일꾼으로 써 무주택자를 위해 집을 짓는 프로그램입니다. 이 과정을 통하여 그들의 신앙을 행동으로 옮기고 예 수님의 사랑과 능력을 전할 수 있습니다.

\section{바. 여성의 집짓기 (Women Build)}

해비타트 건축공정 과정 중 $80 \%$ 이상을 여성의 힘으로 진행하여 여성도 건축현장에서 주도적으로 망치질을 하고, 합판을 나르고, 골조를 세우며 보 금자리 만들어 갈 수 있음을 보여주는 여성 주도 프로그램입니다. 패션쇼와 바자 등을 통해 모든 분 야의 여성들이 다같이 어울려 한마음으로 모금활 동에 참여함으로써 여성들의 행동하는 사랑을 실 천하는 기회를 제공합니다.

\section{0. 후원방법}

- 주택 건축비 후원

-1 세대 주택 건축비

: 7,000 만원 (토지구입비 및 건축비 원가)

- 기업의 수익금 일부 나누기

(예: 수익금의 $1 \%$ 를 건축비로 후원)

- 집고치기 사업 후원

: 열악한 주거환경 개선을 위한 후원금 
- 직원들 스스로 해비타트 운동에 동참하는 동호회를 설립하여 자체 모금활동을 통한 후원

: Matching Grant

(예: 임직원들이 급여의 일부를 모금 + 모금액에 해당하는 금액을 기업에서 매칭하여 후원)
- 현물후원 (Gift-in-Kind)

- 해비타트 주택거축에 필요한 자재공급

- 숙련된 기술 및 용역제공

- 사무기기 지원 및 간식/음료 기타 소모품 후원

- 바자회 행사를 위한 물품후원 